\title{
Da Exclusão à Inclusão Consentida: negros e mulheres na diplomacia brasileira
}

Karla Gobo ${ }^{2}$

\section{Resumo}

Inteligência, sofisticação, gosto apurado, domínio de várias línguas, conhecimentos estabelecidos de arte, cultura e o uso das regras de etiquetas. Esses aspectos, de forma naturalizada, compõem o habitus diplomático. A diplomacia brasileira por muito tempo se manteve fiel às normas e ao espaço que a consagravam e distinguiam do restante da sociedade brasileira, por isso até à redemocratização o Itamaraty era o espelho de sua elite, isso inclui a maioria expressiva de homens brancos. Somente a partir da segunda metade dos anos 1990 se adotam medidas mais efetivas com a preocupação de diversificar os quadros da carreira. Considerando a construção histórica do campo, do habitus diplomático e as medidas adotadas nas últimas décadas, pretende-se investigar as formas de exclusão e inclusão das minorias, sobretudo mulheres e negros. A investigação sobre esse espaço social é fundamental na medida em que a produção acerca desse campo e de seus agentes é bastante escassa. Para a análise foram empregados métodos quantitativos e qualitativos: survey, entrevistas, livros de memórias, biografias, consulta a banco de dados com a origem geográfica e formação escolar, anuários e editais de concurso.

Palavras-chave: Itamaraty. Diplomatas. Burocracia.

\section{Introdução}

Ao longo da história o corpo diplomático brasileiro se constituiu como um campo ${ }^{3}$ distinto do restante da burocracia de Estado. Desde seus primórdios, tratou-se de um campo em que critérios de distinçăo - que

I A primeira versão deste texto foi apresentada no IX Congresso da Associação Latino-americana de Ciência Política.

2 Doutora em Sociologia pela Unicamp. Professora da Escola Superior de Propaganda e Marketing e da Universidade Veiga de Almeida. Pesquisadora do Laboratório Cidades Criativas.

3 O conceito de campo utilizado aqui é aquele frequente na literatura bourdiesiana, que o trata como uma estrutura de relações objetivas, relativamente autônoma dos demais

4 A distinção no mundo social unifica e distancia. Ao passo que a diplomacia brasileira era muito diferente dos seus representados, era também muito semelhante às demais existentes pelo mundo, constituindo uma 
consideravam fluência em línguas estrangeiras, conhecimentos estabelecidos de arte e cultura, naturalidade no uso das etiquetas e nas formas de se vestir - como elementos fundamentais para o exercício da profissão. $\mathrm{O}$ trecho a seguir expressa muito bem o habitus corrente na profissão:

Não eram os diplomatas brasileiros parecidos entre si, como éramos também parecidos com todos os diplomatas do mundo - mas um mundo que consistia em uns quarenta países, dentre os quais talvez uma dúzia ou pouco mais que de fato contassem. Integrávamos uma elite, uma comunidade global que compartilhava estilos e práticas. Essa crème de la crème internacional se entendia em francês, a língua diplomática par excellence. Compreende-se esse tribalismo elitista. Era prático que agissem todos sob um mesmo código e que, literal e metaforicamente, falassem a mesma língua [...] O Itamaraty era então - e sobretudo - a Casa da elite. Diria mais: era o lugar que reunia a elite da elite, e sua legitimação derivava de se perceber e de ser percebida como núcleo de qualidade e excelência. Com a criação do Instituto Rio Branco, deixou de ser uma Casa de elite por seleção aristocrática para ser também uma Casa de elite por seleção intelectual. $O$ conceito de elite não só permaneceu como robusteceu [...] (AZAMBUJA, 20II).

Seja por meio do recrutamento personalista, que vigorou basicamente até a década de 1930, cujos atributos eram o capital cultural e social ${ }^{5}$ dos interessados na carreira. Ou por intermédio do recrutamento racional, depois da adoção do concurso público, em que eliminou ou limitou a importância do capital social, a diplomacia brasileira esperava ser o espelho de sua elite: homens brancos, da zona sul do Rio de Janeiro, cuja sociabilidade se iniciava nos colégios da antiga capital, com vivências em outros países ${ }^{6}$.

"unidade global que compartilhava estilos e práticas". Em outras palauras, independente das diferenças culturais ou de nacionalidade, cultivam-se traços distintivos capazes de unir os "diplomatas do mundo", ou do mundo que importa: aqueles que dentre outras coisas, têm em comum o culto e a valorização dos signos mais consagrados nas sociedades ocidentais, sobretudo de origem europeia com acento francês. A cumplicidade $e$ familiaridade entre eles está fundada numa comunidade que thes confere coesão e que vai além dos interesses profissionais, compartilhando-se valores, uma forma de ser e de apreciar, inclusive em nivel inconsciente.

5 Esses dois tipos de capital constituem aquilo que Bourdieu chamou de capital simbólico que é [...] uma propriedade qualquer (de qualquer tipo de capital; físico, econômico, cultural, social), percebida pelos agentes sociais cujas categorias de percepção são tais que eles podem entende-las (percebê-las) e reconhecê-las, atribuindo-Ihes valor)." (BOURDIEU, 2005, p. 107).

6 É exemplificativa a matéria sobre a morte de Manoel Pio Côrrea, no jornal Folha de São Paulo: "Ao lado da família, o carioca Manoel Pio Corrêa conheceu os cinco continentes ainda criança. Seu pai, um famoso botânico de mesmo nome, viajava o mundo como pesquisador do museu de história natural de Paris à procura de plantas desconhecidas. Grande conhecedor da Revolução Francesa, era dono de cerca de 1.000 publicações só sobre o tema, em diferentes línguas - falava pelo menos seis, além do português". Disponivel em: http://www I.folha.uol. com.br/cotidiano/20 /3/I2//3856 I I-manoel-pio-correa-jr-19 /8-20 /3--o-diplomata-as-viagens-e-os-liuros.shtml 
Entretanto, o discurso do mérito presente na segunda metade do século XX foi aliada ao discurso da representação depois da redemocratização, sobretudo a partir da metade da década de 1990. Nota-se a preocupação de que esse grupo passe a representar uma parcela mais ampla da população brasileira. O discurso do orador de turma, que foi também bolsista do programa de ação afirmativa, João Lucas Ijino Santana, na formatura de 2015, explica:

Consequência direta do maior peso e presença do Brasil no mundo foi a necessária ampliação de nossos quadros. Em 2005, o Ministério contava com 1.008 diplomatas. Hoje, somos 1.569, dos quais 912 se encontram em postos fora do País. Essa geração que ingressou no Serviço Exterior, ao longo da última década, representa um novo perfil de profissional, que, dada sua grande diversidade, marca uma renovação geracional que é benéfica para o conjunto da Instituição. Somos muitos e falamos com diversos sotaques. Professamos várias crenças e professamos crença alguma. Somos pretos, brancos e pardos. Somos homens e mulheres e nascemos e criamo-nos em lares cujo nível de prosperidade deixou de ser um diapasão para tornar-se um amplo gradiente de circunstâncias familiares que engloba, fraternal e solidariamente, os que tiveram mais e os que tiveram menos oportunidades de crescimento pessoal ao longo da vida. Isso é bom para o Brasil e isso é bom para o Itamaraty? (SANTANA, 2015).

Esse discurso vem acompanhado de medidas efetivas para a diversificação, como: eliminaçáo de provas orais, inclusive de idiomas; nomeaçáo imediata; criação de bolsas de estudo para afrodescendentes; reconhecimento de união de pessoas do mesmo sexo para remoçóes e plano de saúde; fim das barreiras institucionais que impediam a promoçáo de mulheres; estímulo à promoção de mulheres; eliminação do critério etário; reserva de vagas para deficientes físicos, entre outras.

Tendo em vista essas mudanças, neste artigo o objetivo é analisar duas minorias na instituição: mulheres e negros. Para isso foram empregados métodos quantitativos e qualitativos. Dentre eles, um survey com 208 diplomatas, para o levantamento de estatísticas descritivas. Além de um banco de dados com todo o universo de diplomatas até 2015, nele estão contidas informaçôes como local de nascimento, formação, ano de entrada

7 Disponivel em: http://www.itamaraty.gou.br/index.php?option=com_contentEview=articleEid=10789\%3A discurso-do-secretario-joao-lucas-ijino-santana-orador-da-turma-paulo-kol-20/3-20/5-do-instituto-rio-brancobrasilia- 12 -de-agosto-de-20 15 Ecatid=206EItemid=460Elang=pt $-B R$ 
na carreira. Para a coleta de dados qualitativos foram consideradas entrevistas, memórias, biografias. Os conceitos utilizados aqui são aqueles clássicos encontrados na literatura bourdiesiana, como: campo, distinção e capital simbólico.

\section{O princípio da representação diplomática}

Até à Reforma Oswaldo Aranha, em 1938, o Ministério tinha dois corpos: o Corpo Consular e o Serviço Diplomático. O primeiro gerava recursos e emolumentos, enquanto o segundo estava mais focado nas açóes de representação do Estado. A carreira diplomática era aquela que dependia de indivíduos que estivessem próximos ao centro de poder e que pudessem dispensar seus recursos para representar o País.

Os presidentes da Primeira República precisavam de um corpo diplomático forte para lidar com as graves questóes fronteiriças da época. Para tanto, buscaram inicialmente os membros da elite imperial responsáveis pela política externa. Entre esses, papel destacado foi dado ao Barão de Rio Branco. Num país dominado por instituiçôes oligárquicas, Rio Branco sabia que sua posição e de seus comandados eram frágeis. Por isso o ministro (1902-1912) barganhou um status diferente para a diplomacia, como estrutura permanente de Estado. Esse processo continuou depois de sua morte e, na década de 1920, Maurício Nabuco, membro de carreira, liderou a consolidação das características de uma burocracia weberiana do Itamaraty (LOUREIRO; ABRUCIO; PACHECO, 2010).

Naquele início de República, além do capital cultural e social, dois outros elementos objetivos influenciavam as chances dos candidatos, impactando não só a seleção, mas também a distribuição dos postos: a cor da pele e a aparência física. Alguns autores destacam a sorte do diplomata Oliveira Lima $^{8}$, diplomata classificado como empenhado e competente, que se viu

8 De acordo com Gôuveia (1976, p. 17): "Partiram de Oliveira Lima as primeiras memórias em favor do alargamento dos mercados dos produtos básicos do Brasil - o açúcar e o café -, e não só ao Itamaraty, mas também ao Ministério da Agricultura que na época englobava os negócios da Indústria e do Comércio, fornecia o diplomata noticias detalhadas das conquistas tecnológicas e científicas, orientava sobre as oportunidades surgidas no mercado internacional, cuidava atentamente dos interesses nacionais nos paises em que estava acreditado. No exercicio tanto das suas atividades oficiais, como intelectuais, Oliveira Lima não admitia desperdícios de tempo com futilidades sociais - nem mesmo nos primeiros tempos da carreira quis parecer um "salonnard", um adepto do estilo de vida que não raro seduz diplomatas de todas as nacionalidades". 
preterido em alguns momentos por ser obeso “[...] de ter retardado a ascensão de Oliveira Lima - mais do que ele, Barão, obeso - a postos de primeira grandeza na representação do Brasil no estrangeiro." (FREYRE, 2010, p. 144) ou "[...] em lugar das missóes que aspirava, mesmo que fossem trabalhosas, impôs-lhe o Barão postos secundários na América do Sul, reservando os que Lima aguardava para familiares medíocres membros do chamado 'Kitchencabinet.”' (GOUVÊA. 1976, p. 14) Outro exemplo é a escolha de Rui Barbosa para a Conferência de Paz em Haia, não seria uma escolha do Itamaraty, mas sim uma imposição do poderoso Correio da Manhã (FREYRE, 2010). Fica evidente nessas e em outras passagens a importância de que os agentes/representantes da diplomacia estivessem associados aos padróes europeus não somente nos gostos e comportamentos, mas também no tipo físico: brancos, altos e magros (ALONSO, 2007; GOUVÊA, 1976. AZAMBUJA, 2011; AMARAL, 1947; LIMA, 1937). Dessa forma, a carreira diplomática, além de aparecer em alguns estudos como espaço de monarquistas, restrito àqueles que tinham proximidade e acesso aos círculos decisórios na República Velha, exigia também para ingresso "boa aparência” e domínio, com "naturalidade" dos símbolos da cultura legítima.

Se os diplomatas deveriam bem representar D. Pedro II durante o Império, na nascente República eles deveriam espelhar a elite do País, herdeira do Império, socializada com a etiqueta de corte. Como diz o Embaixador Marcos Azambuja "a elite da elite”, sua entrevista na década de 1950 para a carreira é tratada como uma "conversa” com Guimarães Rosa sobre as esculturas de Florença, cidade que o candidato tinha acabado de visitar (AZAMBUJA, 2011).

O recrutamento basicamente personalista cede lugar ao modelo meritocrático, mensurável a partir de editais e regras claras de seleção a partir de 1934. O recrutamento foi retirado das mãos dos políticos, da cúpula da instituição e o estabelecimento de provas escritas não identificadas foram as três medidas que visavam tornar o concurso um processo baseado essencialmente no mérito dos candidatos. Entretanto, o resultado dessa mudança sobre o perfil dos recrutados é pouco expressivo. Pode-se dizer que o objetivo de selecionar os candidatos com alto capital cultural continua 
inalterado, o que se altera é a queda da influência do capital social sobre o processo seletivo'.

Seguindo esse caminho de racionalização do recrutamento burocrático, em 1945 foi criado o Instituto Rio Branco, por meio do DecretoLei no 7.473 , de 18 de abril de $1945 .{ }^{10}$ Se é possível dizer que diminui, até quase à extinção, o poder do capital social, o capital cultural se firma como fundamental para aqueles que têm o objetivo de ocupar um espaço na instituição. Dizer que o processo tenha se tornado meritocrático não implica que o acesso ao campo diplomático tenha se tornado universal, já que mulheres, negros, minorias sexuais, homens brancos de baixa estatura, mais velhos ou com deficiência foram, de diferentes maneiras, excluídos desse espaço. De 1938 a 1954, as mulheres não foram admitidas na carreira. Há também relatos de entrevistas que buscavam, além de medir o capital cultural, limitar o acesso de negros, de gays e de lésbicas. "Tinha um colega nosso, Embaixador, que fazia parte dessa banca, e o apelido dele era deer hunter (caçador de "veados", isto é, homossexuais). " (Diplomata anônimo 1, 2014). Essas tentativas de exclusão perduraram até 1984, quando findam as entrevistas. Mas somente a partir de 2005 são eliminados todos os exames orais. O Embaixador Marcos Azambuja assim define sua experiência sobre o concurso de admissão ainda na década de 1950:

A liturgia dos exames de admissão ao Instituto Rio Branco era cercada de pompa e circunstância. As vagas anuais não costumavam ultrapassar uma dúzia e meia, e o número de candidatos que se apresentavam beirava o milhar. Havia primeiro os exames psicológicos que, além de excluir os desequilibrados mais evidentes, tinham um objetivo acessório veladamente homofóbico. (AZAMBUJA, 2011).

9 Se o interessado na carreira tivesse um alto capital social, era tolerado seu baixo capital cultural, caso contrário ele deveria comprovar seu mérito por meio do domínio naturalizado deste capital. Em resumo, caso não houvesse evidência de seu alto capital cultural e econômico era preciso um altíssimo capital social, que se confirmava por intermédio de relações muito próximas, geralmente de parentesco, com os aqueles que ocupavam o centro do poder, inclusive presidentes da república.

10 Neste Decreto-Lei fica estabelecido que o órgão seria um centro de investigações e ensino. Suas funções seriam: a) a formação, o aperfeiçoamento e a especialização de funcionários do Ministério das Relações Exteriores; 0 preparo de candidatos ao concurso para a carreira de "Diplomata"; a realização, por iniciativa própria, ou em mandato universitário, de cursos especiais dentro do âmbito dos seus objetivos; a difusão, mediante ciclos de conferências e cursos de extensão, de conhecimentos relativos aos grandes problemas nacionais e internacionais; a sistematização de dados e documentos e a realização de pesquisas sobre história política e diplomática. 
Em resumo, a mudança no recrutamento não levou necessariamente à mudança no perfil dos atores recrutados, pois a avaliação visava selecionar justamente agentes muito semelhantes aos que lá estavam (CHEIBUB, 1984, 1985). A diplomacia do Itamaraty passou de um recrutamento tradicional, selecionando os jovens de famílias tradicionais da elite imperial, inclusive na recém-criada República, para uma seleção de tipo racional-legal. No entanto, apesar das mudanças institucionais no recrutamento, o perfil dos agentes que compóem o Ministério das Relaçóes Exteriores não sofreu grandes alteraçóes no que diz respeito à origem social e geográfica.

\section{Mulher diplomata}

Pautando-se no artigo 1973 da Constituição de 1891, o qual dizia que "todos os brasileiros" poderiam pleitear um cargo público, Maria José de Castro Rebello Mendes, em 1918, torna-se a primeira mulher a ingressar no Itamaraty. Os argumentos antifeministas à época chamavam a atenção de que o plural masculino não incluía a mulher. Os arranjos de significados que foram conferidos ao termo masculino "brasileiro" variavam de acordo com cada situação. Enquanto o plural de "brasileiro" deixava de fora as mulheres, o Código Penal as reconhecia na qualidade de autora e ré.

De 1919 até a reforma Graça Aranha de 1938, quando o concurso foi expressamente proibido para mulheres, 18 delas tinham ingressado na instituição. Somente em 1953 uma mulher entrou por força de um mandado de segurança. Em $1954^{11}$ foi finalmente extinta a proibição. Entretanto, no primeiro concurso do Instituto Rio Branco, em 1945, não se colocou em edital tal proibição, gerando o seguinte constrangimento:

No início de abril, o Instituto ainda era celebrado por abrir "as portas a quantos queiram se inscrever sem distinção de sexo e de casta", mas já funcionava um processo de "severa seleção de documentos", como afirmou um servidor, para diminuir o número de candidatos indesejáveis no certame. Em 16 de abril, após o encerramento das inscrições, e menos de duas semanas antes do início das provas, partiu da Presidência da República, mais especificamente de Gabriel Monteiro da Silva, chefe da Casa Civil, a determinação de que "sendo pensamento do governo não admitir mais o ingresso de funcionários do sexo feminino à carreira de diplomata", o Itamaraty deveria evitar matrícula definitiva no Instituto Rio Branco de mulheres até que fosse publicado um Decreto-Lei que legalizasse a proibição. Essa

11 Lei n 2.171, de 18 de janeiro de 1954. 
medida claramente afrontava a legislação vigente. Várias mulheres já haviam recebido a guia de exame médico para o concurso. [...] As "providências" foram negar as inscrições para as que obtiveram sucesso na prova. (FARIAS; CARMO, 2015, p. 57-59).

A proibição de mulheres gerou impactos profundos sobre a instituição no que diz respeito à equidade entre os sexos. O reflexo disso pode ser visto na tabela a seguir:

Tabela I - Gênero dos diplomatas aposentados (2015)

\begin{tabular}{lcccc}
\hline Cargos & Homens & \% & Mulheres & $\%$ \\
\hline Embaixadores & 184 & $75,4 \%$ & 9 & $26,5 \%$ \\
Ministros de Segunda Classe & 24 & $9,8 \%$ & 4 & $11,8 \%$ \\
Cônsul & 32 & $13,1 \%$ & 17 & $50,0 \%$ \\
Primeiro Secretário & 3 & $1,2 \%$ & 0 & $0,0 \%$ \\
Segundo Secretário & 1 & $0,4 \%$ & 4 & $11,8 \%$ \\
Terceiro Secretário & 0 & $0,0 \%$ & 0 & $0,0 \%$ \\
\hline Total & $\mathbf{2 4 4}$ & $\mathbf{1 0 0 , 0 \%}$ & $\mathbf{3 4}$ & $\mathbf{1 0 0 , 0 \%}$ \\
\hline
\end{tabular}

Fonte: Elaboração da autora a partir do banco de dados de diplomatas aposentados

Em 2012, 278 diplomatas estavam aposentados. Desses, somente $12,2 \%$ eram mulheres. Como se pode notar, a proibição ou dificuldades não se restringiam ao ingresso na carreira. Ela se estendia à vida institucionalizada, já que havia uma série de barreiras que limitavam sua ascensão na carreira.

Até meados dos anos 1980, caso a mulher diplomata se casasse com um colega de carreira - situaçáo bastante comum quando se removido de posto, que significa na maioria das vezes de país a cada três ou quatro anos - e seu marido fosse removido, ela era obrigada a "agregar", já que não era permitido que os dois servissem no exterior. $\mathrm{O}$ ato de agregar consiste em acompanhar o cônjuge sem remuneração e nem direito ao tempo de serviço. Em outras palavras, ficar com a carreira suspensa. $\mathrm{O}$ regulamento não determinava quem dos dois deveria agregar, mas na unanimidade dos casos quem agregava era a mulher. Essa medida as obrigava a escolher entre a profissão e o matrimônio, tornando os dois irreconciliáveis. Abolida essa forma, outras foram mantidas até a segunda metade dos anos 1990, quando 
se eliminou a proibição de casais servindo no mesmo posto ou retirada das verbas de representação, que constituem boa parte dos salários dos lotados no exterior, das profissionais casadas com diplomatas.

Como se pode ver no quadro apresentado, essas barreiras impactaram sobremaneira a carreira dessas mulheres. Enquanto 75,4\% dos homens alcançaram o grau mais elevado o mesmo ocorreu para apenas $26,5 \%$ das mulheres. Em 1996, apenas três mulheres eram embaixadoras, de um total de 98 embaixadores. Em 2005, entre os embaixadores brasileiros somente nove diplomatas eram do sexo feminino. No entanto, em 2011 já eram 26 $6^{12}$. Nesse mesmo ano, das nove nomeaçóes para Ministro de Primeira Classe $^{13}$, quatro eram de mulheres, alcançando assim $20 \%$ do contingente de Embaixadoras. Nos últimos dez anos, 25 diplomatas foram promovidas a Ministras de Primeira Classe. ${ }^{14}$ Nos dias atuais, a representação de mulheres na carreira está distribuída da seguinte forma:

Tabela 2 - Proporção de diplomatas ativos, por sexo (2015)

\begin{tabular}{lcc}
\hline Sexo & $\mathbf{N}$ & $\%$ \\
\hline Homens & 1216 & $77,7 \%$ \\
Mulheres & 349 & $22,3 \%$ \\
\hline Total & $\mathbf{1 5 6 5}$ & $\mathbf{1 0 0 , 0} \%$ \\
\hline
\end{tabular}

Fonte: Banco de dados dos diplomatas ativos (2015)

12 BALBINO (20II) aponta que o problema da representação feminina na diplomacia não é um fenômeno exclusivamente brasileiro. Embora melhor, nos EUA também não se tem equidade. Nesse país as mulheres ocupavam, em 2005, 35,8\% do contingente e "na vizinha Argentina, havia 209 diplomatas do sexo feminino $(21,8 \%)$ entre os 960 no total. Comparativamente, dois países em que a situação de representação feminina na carreira diplomática é mais expressiva são os também vizinhos Paraguai, com 37,4\% de mulheres entre seus 289 diplomatas e Bolivia, onde as mulheres representam 41,6\% (82 diplomatas do sexo feminino) dos 197 diplomatas em serviço no ano de 2005. Sobre o Paraguai, cabe observar que apenas 47 dos 289 diplomatas foram selecionados por concurso público, realizado pela primeira vez em 2003. E, entre esses, as mulheres foram maioria: 26 entre 47, ou 55,3\%" (BALBINO, 20II, p. 49).

13 Dados informados por Hermano Telles Ribeiro (Secretário de Planejamento Diplomático), em junho de 20II, informam que foram promovidas as seguintes embaixadoras: Carmen Lídia Richter Ribeiro Moura. Gláucia Silveira Gauch, Mariangela Rebuá de Andrade Simões e Eliana Zugaib.

14 De acordo com os dados de 2013, as lotações das Ministras de Primeira Classe foram, por exemplo, o Consulado-Geral em Zurique, Embaixada em Wellington, Embaixada em Praia, Ministério da Justiça. Consulado- Geral em Santiago, Embaixada em Berna. Missão Junto às Nações Unidas, Consulado-Geral em Buenos Aires, Ministério da Previdência Social, Consulado-Geral em Bruxelas, Embaixada em Estocolmo, Delegação Permanente junto à UNESCO. Embaixada em Luanda, Embaixada em Abidjan, Subsecretaria Geral Política II, Embaixada em Mascate, Embaixada em Abuja, Delegação Permanente em Genebra. Missão Junto às Nações Unidas, Tribunal Superior Eleitoral, Consulado-Geral de Rivera, Embaixada em Adis Abeba. 
A dificuldade de alcançar os postos mais elevados não se dava apenas pelas restriçôes. Para figurar nessas listas de promoçôes aos cargos mais altos é necessário ter tempo de casa e também concluir o Curso de Altos Estudos (BALBINO, 2011). É preciso também capital social entre os colegas, aspecto em que as mulheres do Itamaraty têm mais dificuldade. Muitas delas equilibram as funçóes de diplomata, responsável pela casa e esposa de diplomata, enquanto os homens têm mais tempo livre para socializar com os colegas de profissão.

O relato de uma diplomata exemplifica as dificuldades das mulheres em conseguir conciliar o desenvolvimento do seu capital social na carreira com os papéis que têm que desempenhar no âmbito privado:

Eu queria tanto a minha carreira que eu fazia qualquer coisa, pagava qualquer preço, eu construí a casa, eu cuidava dos meninos, e ele só fazia o trabalho dele. E era assim, ele estava em casa no domingo lendo o jornal e ninguém incomodava porque ele estava trabaIhando e a gente fazia todo o resto, leva menino pra médico, pra dentista, trabalha. [...] Até me lembro de uma coisa muito interessante, muito curiosa, um dia eu estava no trabalho e a babá me liga de casa, e diz: o "XXXXX tá com um febrão", não sei o que é, então falei: "bom, então vou lá ver o que é". Saí, passei no banheiro, encontrei uma amiga minha, a XXXXX, um pouco mais velha do que eu... eu disse: o "XXXXXX está com um febrão", então eu estou indo correndo em casa. Daí XXXXXX nem falou nada, nem me perguntou nada, sabe o que ela me disse? "Você não diga a ninguém que vai levar seu filho ao médico, diga que você vai ao cartório". Todo mundo respeita se você for ao cartório, agora se você for ao médico... ai é: "...as mulheres na carreira, olha ai". Se um homem sair para levar o filho ao médico é um pai esmerado, atencioso, homem dedicado, etc... se for a mulher... (Entrevista concedida em 24 de novembro de 2014. Diplomata anônimo 2).

Esses aspectos também aparecem no survey realizado com 208 diplomatas brasileiros. Quando perguntados se a carreira era diferente para mulheres, 54\% dos homens disseram não haver diferenças. Enquanto para $85 \%$ das mulheres há diferenças. Dentre os aspectos apontados estão: 
Tabela 3 - Diferenças na carreira para homens e mulheres

\begin{tabular}{|c|c|c|c|c|}
\hline Temas & Mulheres & $\%$ & Homens & $\%$ \\
\hline Vida pessoal e maternidade & 31 & $25 \%$ & 43 & $35 \%$ \\
\hline $\begin{array}{l}\text { Tomada de decisão/maior dedicação ao } \\
\text { trabalho }\end{array}$ & 11 & $9 \%$ & 6 & $5 \%$ \\
\hline Preconceito, machismo, sexismo, assédio & 17 & $14 \%$ & 14 & $11 \%$ \\
\hline Mulheres são favorecidas nas promoções & 0 & $0 \%$ & I & $1 \%$ \\
\hline Total & 59 & $48 \%$ & 64 & $52 \%$ \\
\hline
\end{tabular}

Fonte: Elaborado pela autora deste artigo

Como se pode ver não há diferenças gritantes entre as temáticas ou a sua importância entre homens e mulheres. Daqueles que afirmam haver diferenças entre os dois grupos, três temas foram mais frequentes: vida pessoal e maternidade, comportamento profissional e preconceitos originários às diferenças entre os sexos. Somente um afirmou que as mulheres são favorecidas nas promoções, numa clara evidência à oposição das políticas de igualdade de gênero dos últimos anos. Apesar da semelhança nas respostas, quando analisadas uma a uma percebe-se que a ênfase maior no grupo masculino é para as questóes relativas às dificuldades em conciliar a vida profissional e maternidade. Enquanto para as mulheres, é bastante citada a dificuldade de contrair e manter uma relação numa carreira que exige mudanças constantes e que dificultam a vida profissional do parceiro. Essa diferença de posicionamento se deve ao fato de que o impacto da maternidade para essas mulheres é menor do que o abalo na vida afetiva, tendo em vista que os altos salários garantidos na carreira diplomática possibilitam a elas a contratação de outras mulheres para cuidar de seus filhos. Com relação ao segundo tema, as mulheres disseram ter maior dedicação ao trabalho, já para os homens as mulheres são diferentes porque são mais prudentes nas tomadas de decisão.

Por estar mais à esquerda do espectro político-ideológico do que seu antecessor (PSDB), o Partido dos Trabalhadores (PT) esteve associado ao desenvolvimento de políticas que atendessem ou mitigassem os problemas das minorias sociais (FIGUEIREDO; LIMONGI, 1995). Entretanto, quando se olha para o caso específico das mulheres no Itamaraty o relato 
é de que, o aumento do número de promovidas ao cargo de embaixadora não foi uma política que pode ser atribuída ao PT. As entrevistadas contrariaram essa hipótese inicial ao afirmar que esse processo se deu pela ação do Ministro Celso Amorim (2003-2010), que se preocupava com a diminuição da desigualdade de gênero na casa. Umas das entrevistadas registrou que

[...] foi algo não escrito, mas foi uma política do Embaixador Celso Amorim, ele fez e ele disse isso de uma forma muito bonita, que eu gravei que me emocionou muito: "As mulheres não eram promovidas, não porque não eram competentes, elas eram mulheres, e agora eu estou promovendo não porque elas são mulheres, mas pela competência." (Entrevista concedida em outubro de 2014. Diplomata anônima 3).

Essa atribuição à figura do chefe da casa e não a uma política de governo pode ser verificada na fala a seguir, em que a entrevistada diz ter acompanhado o processo. Mesmo no mandato de uma presidenta também do PT, os ministros que sucederam a Celso Amorim não deram continuidade à política implantada em sua gestão.

[...] o Celso realmente fazia questão de em cada lista de promoção, isso eu presenciei, dizendo: quantas mulheres? Na votação para o quadro de acesso tinha um número, primeira era a votação, tinha uma cota para mulheres, depois para postos $b$, que era para quem estava nos postos mais dificeis eram as mulheres, então você matava dois coelhos com uma pedrada só. A outra coisa que ele fez, também muito importante, foi colocar mulheres em posições elevadas. Ele colocou a primeira mulher a ser embaixadora na ONU; subsecretaria, o meu caso; a primeira embaixadora na Santa Sé, que foi a Vera. Ele promoveu muito a mulher, muito, muito mesmo, eu acho que é preciso dar a ele esse crédito [...]. Depois disso o que nós temos notado, embora os sucessores sejam da minha geração, meus colegas, essa tendência não foi seguida. (Entrevista concedida em novembro de 20 I4. Diplomata anônima 2).

É importante ressaltar que políticas afirmativas com o intuito de minimizar as desigualdades não é uma exclusividade brasileira. A medida do ministro não está distante da observada em outros países. Na França, por exemplo, também ocorreram açóes semelhantes. Em 2003, as mulheres francesas embaixadoras eram apenas 14\%. Em 2015, já compunham $30 \%$ do total de embaixadores e a projeção é de 40\% para 2017 (LEQUESNE, 2016). 
Como se pode ver, mesmo depois da eliminação das barreiras que limitavam o acesso e a ascensão das mulheres na carreira, elas não são ainda nem um quarto do corpo diplomático brasileiro e nem ocuparam os postos mais importantes da carreira como a de Secretaria Geral, a Embaixada em Washington, da Argentina ou da França. O caso de sucesso mais expressivo é de Maria Luíza Viotti, nomeada Embaixadora do Brasil na ONU em Nova York.

Uma hipótese é que menos mulheres fazem o processo seletivo do Instituto Rio Branco, em comparação com a carreira de oficial de chancelaria. A hipótese inicial seria a dificuldade de conciliar a vida profissional e pessoal. No entanto isso parece questionável quando se olha para outro cargo do Ministério das Relaçóes Exteriores, o de oficial de chancelaria. Embora em grau um pouco menor, também se está exposto ao principal constrangimento da vida diplomática: as remoçóes. É um cargo em que não se desempenha funçóes de mando e em grande medida se restringe à tarefa de secretariar os diplomatas. Nessa função, o número de mulheres supera e muito o número de homens. Em 2005, essa carreira contava com $60,5 \%$ de mulheres contra $19,4 \%$ de mulheres diplomatas, no mesmo período. Em 1993, as aprovadas eram 21\% do total. Em 2010, com a seleção de 100 aprovados, o percentual de mulheres não ultrapassou $25 \%$. O ano em que as mulheres tiveram maior sucesso foi 2008, com 31 de 115 aprovados, compondo um percentual de $26,96 \%$. Antes de 2005 e da abertura de 100 vagas anuais, as mulheres não ultrapassavam 19,28\% da casa. Com o preenchimento de 500 novas vagas o percentual não excedeu os $23 \%$.

Tabela 4 - Divisão sexual, por governo

\begin{tabular}{lcccccc}
\hline Sexo & $\begin{array}{c}\text { Governo } \\
\text { Militar }\end{array}$ & $\begin{array}{c}\text { Governo } \\
\text { Sarney }\end{array}$ & $\begin{array}{c}\text { Governo } \\
\text { Collor/Itamar }\end{array}$ & $\begin{array}{c}\text { Governo } \\
\text { FHC }\end{array}$ & $\begin{array}{c}\text { Governo } \\
\text { Lula }\end{array}$ & $\begin{array}{c}\text { Governo } \\
\text { Dilma }\end{array}$ \\
\hline Homens & $79,4 \%$ & $80,6 \%$ & $81,3 \%$ & $83,2 \%$ & $75,3 \%$ & $75,8 \%$ \\
Mulheres & $20,6 \%$ & $19,4 \%$ & $18,7 \%$ & $16,8 \%$ & $24,7 \%$ & $24,2 \%$ \\
\hline Total & $\mathbf{1 0 0 , 0 \%}$ & $\mathbf{1 0 0 , 0} \%$ & $\mathbf{1 0 0 , 0} \%$ & $\mathbf{1 0 0 , 0 \%}$ & $\mathbf{1 0 0 , 0 \%}$ & $\mathbf{1 0 0 , 0 \%}$ \\
\hline
\end{tabular}

Fonte: Elaborado pela autora deste artigo a partir do Banco de Dados dos Diplomatas Ativos

Embora a primeira impressão fosse de que o aumento de aprovadas na carreira seria gradual a partir da eliminação da proibição das barreiras 
internas e dos estímulos à ocupação dos espaços pelo movimento feminista, isso não se verifica. $\mathrm{O}$ percentual permanece razoavelmente estável, com a aprovaçáo inclusive mais baixa no período de 1995-2002 e o pico nos anos do governo de Luiz Inácio Lula da Silva (2003-2010).

Com relação ao processo seletivo, o aumento do número de mulheres não se dá depois da eliminação das entrevistas em 1984, como se poderia supor num primeiro momento, mas quando se elimina qualquer prova oral para a entrada na carreira. Com eliminação dessa modalidade de avaliação se observa um aumento de 4,9\% no número de mulheres aprovadas de um governo para o outro. Com base nesse dado, acredita-se que os exames orais tendem a limitar o acesso de mulheres à carreira. Isso talvez se dê pelos critérios subjetivos da banca ou porque as mulheres são menos treinadas, têm mais dificuldades e são mais rigidamente avaliadas quando falam em público. Ao contrário dos homens, além de ter que discorrer sobre os conhecimentos do concurso, as mulheres eram expostas a questóes como filhos e casamento, que eram perguntadas exclusivamente a elas:

Eram um obstáculo terrível. Também para os homens, mas para as mulheres em especial. Eles sempre perguntavam: "Quê que vai acontecer?"; "Vai continuar na carreira? Não vai? Como é que vai ser se você casar? Como vai fazer com o seu marido? Como vai continuar: isso aqui é uma coisa que você está interessada agora, vai largar” [...]. Também faziam com os homens, mas com as mulheres eram piores [...]. E ficaram perguntando: "Se seu marido for dentista, se seu marido...”. E eu: “Nem sei se vou me casar!" [...] A mesma coisa acontece com os homens - e se a mulher for arquiteta, engenheira? Terão o mesmo tipo de problema que a mulher. Quer dizer, o mesmo tipo de problema se coloca para os homens, mas isso nunca era perguntado para eles. Era uma coisa bastante desigual. (BALBINO, 20 I I, p. I I8).

Embora não note discriminação evidente no que diz respeito à eliminação de homens e mulheres, a percepção das mulheres era de que o obstáculo a ser transposto para quem divergia do grupo majoritário no campo diplomático era maior (BALBINO, 2011). Os questionamentos acerca da vida privada, casamento e filhos eram mais frequentes para o sexo feminino. Em outra entrevista também foi relatado outros tipos de constrangimentos. Numa seleção no final dos anos 1970, foi pedido para uma candidata tirar a sua blusa.

[...] fora o exame acadêmico [...] depois você tinha esse exame com a banca, que era uma coisa que intimidava. Eu me lembro que a gente era exposta a situações terríveis, eu me 
lembro que eu entrei na banca, uma banca de umas oito pessoas, era de uniforme, tinha médico também, etc... entrei na banca e um militar disse: "a senhora tire a blusa". Aí eu disse: "bom... é... eu vou precisar repetir algum exame médico?’ Dai ele disse assim: "suponha que sim e suponha que não". Eu disse: "na suposição que eu tenha que fazer um exame médico, por favor me encaminhe para o lugar onde eu serei examinada, supondo que eu não vou fazer nenhum exame médico não vejo razão de eu tirar a blusa". (Entrevista concedida em novembro de 2014. Diplomata anônima 2).

Como se pode ver até aqui, as mulheres têm que apresentar outras disposições num campo histórico e marcantemente masculino. A elas não basta ser boa profissional. Elas têm que lidar com outras variáveis exclusivas, fruto da desigualdade estrutural entre os gêneros, que são reproduzidas no interior desse espaço social.

\section{Os negros diplomatas}

A questão dos negros é ainda mais difícil do que das mulheres, dada a desigualdade brasileira que atinge, sobretudo, as parcelas não brancas da população. Se não bastassem as exigências do concurso, que o tornam muito difícil para pessoas com baixo capital econômico e pouco investidas do capital cultural legitimado. É preciso frisar que há uma dificuldade adicional em se analisar esse grupo no Itamaraty: não há dados disponíveis sobre autodeclaração de cor. Os dados apresentados aqui são de fontes secundárias, notícias ou do site do Ministério das Relaçôes Exteriores. De acordo com os dados do IBGE (2015), 54\% da população do Ppís é negra ou parda. $\mathrm{O}$ único dado primário obtido aqui por meio do survey demonstra que esse percentual não chega a 20\% no Itamaraty. Apenas um entrevistado se declarou negro e outro amarelo. Outros 39 se afirmaram pardos - aproximadamente $18,8 \%$. Os outros 167 são de brancos, 80,3\% do total. Esses números evidenciam a clara desproporção de acesso e representação nesse espaço.

Além da nossa estrutura societal que torna ests campo de difícil acesso ao grupo não branco, as entrevistas realizadas no processo seletivo foram destacadas como sendo um meio efetivo de supressão daqueles que, devido à cor da pele, náo eram considerados representantes da "elite da elite". A primeira denúncia de discriminação racial foi em 1946, realizada por parlamentares (FARIAS; CARMO, 2015). Outra foi no exame 
psicotécnico de Joaquim Barbosa, de 7 de julho de 1980. A questão da cor da pele aparece no relatório do avaliador que informa que o candidato "[...] tem uma auto-imagem negativa, que pode parcialmente ter origem na sua condição de colored". Na entrevista com diplomatas havia uma avaliação da aparência, a qual Joaquim Barbosa foi descrito como regular ${ }^{15}$.

A primeira nomeação de um embaixador negro só se deu ao final da gestão do Ministro Celso Amorim, em 2010. Benedicto Fonseca Filho, 47, passou no concurso aos 22 anos. O Embaixador tem uma trajetória pouco convencional para esse grupo e que certamente o capacitou para o processo seletivo. Filho de um funcionário da instituição, agente de portaria, ele teve oportunidade de estudar em instituiçóes internacionais.

Foi essa experiência internacional que me despertou o interesse pelo Itamaraty. Talvez por ter estudado em escolas internacionais, na escola francesa e na americana. [...] Tive oportunidades que raramente os negros têm. Morei no exterior, estudei idiomas com a ajuda do Itamaraty, porque ajudavam nos estudos dos filhos dos funcionários. (FONSECA, 20I I).

De acordo com os dados, o Itamaraty é um espaço tão restrito que em 2003 apenas $0,7 \%$ dos diplomatas brasileiros pertenciam ao grupo não branco $^{16}$. Em 2002, último ano da gestão Fernando Henrique Cardoso, foi implementado um projeto de bolsas para afrodescendentes. Denominado "Bolsa Prêmio de Vocação para a Diplomacia"17 o programa prevê o pagamento de uma bolsa durante o período de um ano no valor de $\mathrm{R} \$$ $25.000^{18}$, valor pouco superior a $\mathrm{R} \$ 2.000,00$ mensais, dos quais apenas $30 \%$ sáo admitidos para o custeio. $\mathrm{O}$ restante deve ser destinado a materiais de estudos, cursos ou aulas particulares.

15 Disponivel em: http://espaco-vital.jusbrasil.com.br/noticias//00637202/como-e-quando-o-itamaraty-discriminoujoaquim-barbosa

16 UOL. Negros contam com o apoio de intelectuais para ingressar no Itamaraty. 2003. Disponivel em: http:// wwwl.folha.uol.com.br/folha/dimenstein/imprescindivel/dia/gd060203.htm.

17 Em discurso em dezembro de 200I, o Presidente da República afirma: "Quero Ihes dizer que a Secretaria de Estado dos Direitos Humanos vai apoiar um programa de ação afirmativa no Instituto Rio Branco, que é o responsável pela formação dos diplomatas brasileiros. Serão concedidas 20 bolsas de estudos para afrodescendentes para que se preparem, especificamente, para o concurso que haverá - como há todo ano - no Itamaraty. Precisamos ter um conjunto de diplomatas - temos poucos - que sejam o reflexo da nossa sociedade, que é multicolorida, e não tem cabimento que ela se apresente pelo mundo afora como se fosse uma sociedade branca, porque não é." (CARDOSO, 200I, p. 728).

18 Este valor da bolsa foi reajustado em 2003, já no governo Luiz Inácio Lula da Silva. Em 2002, o auxílio era de $R \$ 15.000$. O número de bolsas também passou de 20 para 30 anuais. 
Para conseguir uma dessas bolsas os candidatos têm que se inscrever através da Internet no site do CESPE-UnB e escrever uma lauda de redação sobre sua experiência como afrodescendente. Posteriormente, é preciso passar por um processo seletivo em duas etapas. A primeira é uma prova objetiva de Português, Noçóes de Política Internacional e História do Brasil, realizada em várias capitais. A segunda é uma entrevista ${ }^{19} \mathrm{com}$ os aprovados na primeira etapa, que acontece apenas em Brasília e com as despesas pagas pelo Instituto Rio Branco. Nessa etapa os candidatos têm de apresentar: plano, cronograma e orçamento para os estudos. Os demais aspectos avaliados são:

a) formação acadêmica; b) adequação e viabilidade do Plano de Estudos e Desembolso;

c) necessidade de apoio para realização de seus estudos preparatórios ao Concurso de Admissão à Carreira de Diplomata; d) expectativas pessoais sobre a Carreira; e) experiência pessoal do candidato como afrodescendente; f) conhecimento e aceitação dos objetivos do programa. (MRE, 2015). ${ }^{20}$

Os demais requisitos para pleitear a bolsa estão todos os contidos no edital para o concurso mais ter realizado a inscriçáo e se autodeclarar afrodescendente. A bolsa poderá ser renovada até quatro vezes, ${ }^{21}$ desde que o candidato tenha apresentado rendimentos satisfatórios nos concursos de seleção.

19 O diplomata e um dos responsáveis pelo programa esclarece um dos objetivos da entrevista: "Então, quando nós procuramos trabalhar com Bancas de Reparação sobre como se constituiu essa identidade como afrodescendente, a gente quer manter o foco do Programa, a gente não quer que o Programa seja motivo de chacota: "Ah, olha, a loirinha de olho verde ganhou a Bolsa". Não, isso não pode acontecer! Mesmo que ela seja afrodescendente, por quê? Porque no caso do Brasil, a gente sabe que o fenótipo tem muita importância. A pessoa que tem a pele muito clara tem o olho mais claro. Mesmo que seja afrodescendente, ela não vai ser identificada como tal. E isso tem peso na vivência que ela vai ter da sua identidade racial." (OLIVEIRA, 201I, p. 66).

20 MRE. Programa de ação afirmativa. 2015. Disponivel em: http://www.institutoriobranco.mre.gov.br/pt-br/ programa_de_acao_afirmativa.xml.

21 “a) A primeira renovação da bolsa-prêmio é facultada a todos os candidatos sem restrições; b) a segunda renovação da bolsa-prêmio é condicionada a desempenho satisfatório anterior (aprovação e classificação) na primeira fase do CACD; c) a terceira renovação da bolsa-prêmio é condicionada a desempenho satisfatório anterior (aprovação e classificação) na primeira e segunda fases do CACD; d) a quarta e última renovação da bolsa-prêmio é condicionada a desempenho satisfatório anterior (aprovação e classificação) na primeira, segunda e terceira fases do CACD." (disponivel em: http://www.institutoriobranco.mre.gov.br/pt-br/programa_ de_acao_afirmativa.xml). 
As bancas são compostas por representantes do IRBr, diplomatas (ex) bolsistas, da Seppir, do CNPQ e da Fundação Palmares, que trazem representantes para participar do processo seletivo. As Bolsas são concedidas àqueles candidatos e candidatas que obtiverem maior pontuação na escala classificatória da seleção do PAA. (OLIVEIRA, 20II, p. 66).

O site do Instituto Rio Branco traz a seguinte informação: "Até 2014, o Ação Afirmativa já concedeu 594 bolsas para 354 bolsistas, dos quais 21 foram aprovados no CACD." ${ }^{22}$. Levando em consideração o número de bolsistas com o número de aprovados, apenas 6\% deles, mesmo com as renovaçôes, conseguiram a aprovação no concurso. Caso se considere o total de 740 diplomatas ingressos, de 2003 a 2014, esse percentual cai para menos de $3 \%$ dos aprovados. Isso demonstra que, apesar de ser um programa importante, ele ainda não é suficiente para tornar aptas pessoas que estiveram em condiçóes de desvantagem social, econômica e cultural para competir com os demais. Tendo em vista a baixa eficiência do programa, cujas críticas serão analisadas abaixo, em 2011 foram criadas as cotas para a primeira fase do concurso. De acordo com uma diplomata: "o Ministro Celso Amorim sempre quis que o nosso Concurso atingisse mais brasileiros abarcando a toda diversidade do País. Foi uma decisão do nosso Ministro Celso Amorim. Se ele tomou essa decisão é porque estava certo no que estava fazendo." (OLIVEIRA, 2011, p. 78).

Uma das críticas apresentadas ao programa e que pode explicar a baixa aprovação é a desistência dos bolsistas de fazer o concurso.

Para o secretário Márcio, não há como controlar as desistências porque o concurso é gratuito, com a inscrição feita pela Internet. Sendo assim, há o livre-arbítrio para que o candidato possa, no dia da prova, se apresentar para fazê-la. Não há medida punitiva ou que bloqueie essa atitude que, a meu ver, diminui as oportunidades de outrem quanto uma ação afirmativa. (OLIVEIRA, 20I I, p. 69).

Outras apreciações apresentadas é a falta de acompanhamento e tutoria aos bolsistas. As tutorias dependem do interesse e disponibilidade de diplomatas para orientar os beneficiários.

Para compreender o perfil dos beneficiários do programa, de doze diplomatas que foram aprovados no concurso, sete eram do Sudeste, quatro

22 MRE. Programa de ação afirmativa. 20/5. Disponivel em: http://www.institutoriobranco.mre.gov.br/pt-br/ programa_de_acao_afirmativa.xml. 
do Nordeste e um do Centro-Oeste (OLIVEIRA, 2011). Os diplomatas nordestinos apontaram a necessidade de se mudar para São Paulo, Rio de Janeiro ou Brasília em busca dos melhores cursinhos e preparaçáo para a carreira. Muitos relataram que tinham que conciliar os estudos com trabalhos que mantivessem sua subsistência fora de sua cidade, custando-lhes horas de estudos necessárias para alcançar a chance de aprovação. ${ }^{23}$

Sete entre 12 diplomatas passaram por instituições privadas de ensino. Os demais passaram por colégios militares ou escolas de aplicação e apenas um fez sua formação exclusivamente em instituiçóes públicas de ensino. No ensino superior é mantido esse padrão, com dez diplomatas em instituiçóes privadas e cinco em públicas, que são as de mais difícil acesso. Vários desses, os pais conseguiram acessar o ensino superior. Esse dado acrescido dos demais sugerem que a barreira de classe, que dentre elas está no acesso ao ensino superior, foi superada pelos pais desses candidatos que tiveram sucesso no processo seletivo.

Um diplomata entrevistado deixa claro que a bolsa auxilia negros de classe média ou até alta a passar no concurso.

A idéia que tenho, que está até sendo compartilhada entre os demais da mesa, é que não se está atrás do negro que não teve uma base, que não teve uma boa educação. Você está atrás do negro que tem base, que tem chances de passar no concurso. Provavelmente ele será de classe média ou até classe alta e ele, que já tem a possibilidade real de passar, vai ter o reforço da bolsa por um ou dois anos, para se preparar e com esse reforço ele vai poder se dedicar, exclusivamente, à preparação, e se igualar então aos demais concorrentes, que são pessoas de fato que podem se dar ao luxo de depois que concluir a graduação, muitas que já moraram no exterior e etc. e tal, podem se dar ao luxo de estar só estudando até passar em um concurso como o Rio Branco. (OLIVEIRA, 201 I, p. 110).

Ao contrário dos relatos históricos de exclusão, os dados analisados, juntamente com essa fala, deixam evidentes as iniciativas do Ministério

23 "Alguns diplomatas (ex) bolsistas residiram em casas de parentes por algum tempo enquanto conseguiam empregos para se auto-sustentarem nas grandes cidades quando distantes de suas famílias, quatro diplomatas relataram trabalhar ao mesmo tempo em que tinham a bolsa que, no início do programa era de $R \$ 1.500,00$ (Hum mil e quinhentos reais) mensais e só podia custear professores particulares, cursos e material para estudo, mas não cobria gastos como aluguel, despesas com água, luz e Internet. Do grupo entrevistado apenas um diplomata recebia apoio de sua família em forma de recursos financeiros para custear os estudos em outra cidade, mas, em geral, notei que o diplomata que migrava preocupava-se em enviar recursos para apoiar suas familias." (OLIVEIRA, 201 I, p. 95). 
em deixar de ser um espaço majoritariamente de e para pessoas brancas. Essa iniciativa, no entanto, seleciona os afrodescentes capazes de terem capturado grande parte do capital cultural exigido no concurso antes de se tornar bolsista. A medida, portanto, seria voltada para que esse grupo pudesse chegar em condiçóes de concorrer com o grupo branco altamente elitizado.

[...] podemos dividir as respostas dos bolsistas referente à classe média em dois blocos. No primeiro, estão os bolsistas que se reconhecem privilegiados pelo fato de poderem desfrutar e ter acesso a bens sociais e culturais nessa estrutura social profundamente desigual; que frequentaram e conseguiram formação fundamental, médio e superior em instituições escolares de prestígio social; têm domínio de línguas estrangeiras; oportunidades de viajar de férias, em intercâmbios culturais, a estudos e/ou a trabalho; ocupam cargos não-manuais de prestígio social; têm acesso a bens culturais - literatura, arte, cinema, teatro, assinatura de revistas, jornais, acesso à Internet, bens que não são acessíveis a todos; e têm comportamentos e práticas sociais distintos que indicam o habitus da classe média. No segundo, os bolsistas que se reconhecem privilegiados, mas são veementes ao afirmar que não pertencem à classe média ao comparar a sua situação econômica, social e cultura com pessoas por eles consideradas de classe média, ou seja, tendo como "grupo de referência", "extra- grupos", grupos pelos quais eles não se vêem pertencer, grupos que considerem estar excluídos. (LIMA, 2005, p. 93).

Enfim, como se viu, apesar disso, o programa é pouco eficaz se não for conjugado com medidas mais efetivas, como a reserva de vagas, que foi instituída de forma parcial em 2011 e plena a partir do edital de $2015^{24}$.

\section{Considerações finais}

Durante boa parte de sua existência, o Itamaraty foi ocupado basicamente por homens brancos, jovens, heterossexuais ou aqueles capazes de exercer sua homossexualidade com "discrição". Moradores tradicionais da zona sul do Rio de Janeiro, formados em Direito na UFRJ, UERJ ou PUC-RJ, portadores "naturais" da língua e cultura legítimas. O Itamaraty foi descrito pelo Embaixador Marcos Azambuja como uma instituição da "elite da elite", justamente como preconizava o Barão do Rio Branco.

24 No edital de 2015, atendendo à Lei $n^{\circ} 12.990$, de 9 de junho de 2014, voltada a todo os concursos do funcionalismo público, são reservadas $20 \%$ das vagas para candidatos afrodescentes (negros) em todas as etapas do concurso. 
Não havia preocupação em diversificar; era um espaço "naturalmente" excludente. As medidas mais efetivas para a diversificaçáo na carreira ocorreram depois da redemocratização, antes dela apenas havia a preocupação de divulgar e expandir as áreas em que eram realizados os concursos.

A preocupação em tornar esse campo menos homogêneo só aparece nos anos finais no século XX, sobretudo a partir dos governos Fernando Henrique Cardoso e Luiz Inácio Lula da Silva. No governo desse último se nota não apenas a adoção de medidas efetivas como também uma mudança no discurso, que deixa de se referir somente à meritocracia e passa a expor a necessidade de transformar o Itamaraty num espaço que representasse mais a sociedade brasileira, fato inédito até então. Em resumo, pode-se dizer que a diplomacia do Império representava a aristocracia, nos primeiros anos da República os quadros eram da elite social, econômica e cultural. Os cinquenta anos finais do século XX foram marcados pela adoção de discurso e de práticas que privilegiavam o mérito daqueles que tivessem maior apreensão naturalizada da cultura legítima. Somente no século XXI, passa-se a dizer que a diplomacia precisa representar a sociedade brasileira. O resultado é que atualmente há medidas e mudanças efetivas nas regras de recrutamento, no funcionamento interno e também no discurso, mas que ainda não transformaram a instituição de forma substantiva.

\section{Referências}

ALMEIDA, Paulo Roberto. Formaçáo da Diplomacia Econômica no Brasil: As relaçôes econômicas internacionais no Império. Sáo Paulo: SENAC, 2005. 675

ALONSO, Angela. Perfis brasileiros: Joaquim Nabuco. São Paulo: Companhia das Letras. 2007.

AMARAL, Luis Gurgel.. O meu velho Itaramaty: de amanuense a secretario de legação: 19051913. Rio de Janeiro: Imprensa Nacional. 1947. p. 21.

AZAMBUJA, Marcos. Casa bem-assombrada: O Itamaraty antes da sua ida para Goiás. In: Revista Piauí. Edição 54. Março de 2011.

BALBINO, Viviane Rios. Diplomata, substantivo comum de dois gêneros: um retrato da presença feminina no Itamaraty no início do século XXI. Brasília: Fundação Alexandre de Gusmão. 2011. 212 p. 
BOURDIEU, Pierre. Campo de poder e Habitus de classe. In: A economia das trocas simbólicas. São Paulo: Perspectiva. 2007.

Sistemas de Ensino e Sistemas de Pensamento. In: A economia das trocas simbólicas. São Paulo: Perspectiva. 2007.

Reproduçáo Cultural e Reprodução social. In: A economia das trocas simbólicas. São Paulo: Perspectiva. 2007.

Espírito de Estado: Gênese e Estrutura do Campo Burocrático. In: Razóes Práticas. Campinas: Papirus. 2005. p. 91-136.

BRASIL. Anuário do Instituto Rio Branco. 1951: Rio de Janeiro: 1951, 68 p.

BRASIL. Anuário do Instituto Rio Branco. 1952: Rio de Janeiro: 1952, 179 p.

BRASIL. Anuário do Instituto Rio Branco. 1953, 1954, 1955: Rio de Janeiro: 1955, 201 p.

BRASIL. Anuário do Instituto Rio Branco. 1956, 1957: Rio de Janeiro: 1957, 148 p.

BRASIL. Anuário do Instituto Rio Branco. 1958, 1959, 1960: Rio de Janeiro: 1960, 192 p.

BRASIL. Anuário do Instituto Rio Branco. 1961, 1962, 1963: Rio de Janeiro: 1963, 244 p.

BRASIL. Anuário do Instituto Rio Branco. 1964, 1965: Rio de Janeiro: 1965, 186 p.

BRASIL. Anuário do Instituto Rio Branco. 1966, 1967: Rio de Janeiro: 1967, 278 p.

BRASIL. Anuário do Instituto Rio Branco. 1968, 1969: Rio de Janeiro: 1969, 262 p.

BRASIL. Anuário do Instituto Rio Branco. 1970: Brasília - DF: 1970, 209 p.

BRASIL. Anuário do Instituto Rio Branco. 1971: Brasília - DF: 1971, 204 p.

BRASIL. Anuário do Instituto Rio Branco. 1972: Brasília - DF: 1972, 187 p.

BRASIL. Anuário do Instituto Rio Branco. 1973: Brasília - DF: 1974, 175 p.

BRASIL. Anuário do Instituto Rio Branco. 1974: Brasília - DF: 1974, 159 p.

BRASIL. Anuário do Instituto Rio Branco. 1975: Brasília - DF: 1975, 207 p.

BRASIL. Anuário do Instituto Rio Branco. 1976: Brasília - DF: 1976, 184 p.

BRASIL. Anuário do Instituto Rio Branco. 1977: Brasília - DF: 1977, 248 p.

BRASIL. Anuário do Instituto Rio Branco. 1978, 1979, 1980: Brasília - DF: 1980, 257 p.

BRASIL. Anuário do Instituto Rio Branco. 1981: Brasília - DF: 1981, 116 p. 
BRASIL. Anuário do Instituto Rio Branco. 1982: Brasília - DF: 1982, 131 p. BRASIL. Anuário do Instituto Rio Branco. 1983: Brasília - DF: 1983, 125 p. BRASIL. Anuário do Instituto Rio Branco. 1984: Brasília - DF: 1984, 153 p. BRASIL. Anuário do Instituto Rio Branco. 1985: Brasília - DF: 1985,160 p. BRASIL. Anuário do Instituto Rio Branco. 1986: Brasília - DF: 1986, 182 p. BRASIL. Anuário do Instituto Rio Branco. 1987: Brasília - DF: 1987, 259 p. BRASIL. Anuário do Instituto Rio Branco. 1988: Brasília - DF: 1988, 432 p. BRASIL. Anuário do Instituto Rio Branco. 1989, 1990: Brasília - DF: 1990, 325 p. BRASIL. Anuário do Instituto Rio Branco. 2013: Brasília - DF: 2014, 324 p. BRASIL. Anuário do Instituto Rio Branco. 2014: Brasília - DF: 2015, 334 p. BRASIL. Ministério das Relações Exteriores. Edital. Brasília, 2015.

CARVALHO, José Murilo. Os bestializados. São Paulo: Companhia das Letras. 2012. 196 p. CHEIBUB, Zairo Borges. Diplomacia e Construçáo Institucional: O Itamaraty em Perspectiva Histórica. Dados, Rio de Janeiro, n 28, p. 113-131. 1985.

Diplomacia, Diplomatas e Política externa: Aspectos do processo de institucionalização do Itamaraty. Rio de Janeiro, Dissertação de Mestrado, Instituto Universitário de Pesquisas do Rio de Janeiro. 1984.

ELIAS, Norbert. A sociedade de corte. Rio de Janeiro: Jorge Zahar Editores. 2001.

FARIA, Rogério e CARMO, Géssica. Filhos da democracia: A descolonizaçáo da diplomacia brasileira. Mundorama. Disponível em: <https://goo.gl/OPFJhU>. Acesso em 10 de outubro de 2015.

FIGUEIREDO, Argelina e LIMONGI, Fernando. Executivo e Legislativo na nova ordem constitucional. Rio de Janeiro: FGV. 1995.

FREYRE, Gilberto . Ordem e Progresso. Rio de Janeiro: Nova Aguilar Editores. 2010.

GOFFMAN, Erving. Ritual de interaçáo: ensaios sobre o comportamento face a face. Petrópolis, RJ: Vozes. 2012.

LEQUESNE, Christian. Ethnograhie du Quai d'Orsay. Paris: CNRS Editions, 2016. 
LIMA, Oliveira. Memórias: estas minhas reminiscencias. Rio de Janeiro: Livraria José Olympio Editora. 1937.

LIMA, Vera Lúcia Alves Rodrigues. A inserção do negro na carreira de diplomata: ação afirmativa para o Instituto Rio Branco. Dissertaçáo de Mestrado apresentada ao Programa de Pós-graduação em Sociologia e Antropologia do Instituto de Filosofia e Ciências Sociais, da Universidade Federal do Rio de Janeiro. 2005.

LOUREIRO, Maria Rita; ABRUCIO, Fernando Luiz; PACHECO, Regina Silvia (orgs.). Burocracia e política no Brasil: desafios para a ordem democrática no século XXI. Rio de Janeiro: Editora FGV. 2010.

OLIVEIRA, Ana Paula Conceição. Diplomatas Negros (as): Ação afirmativa no Instituto Rio Branco e Trajetória de Diplomatas (ex-bolsistas). Dissertação de mestrado presentada ao Programa Multidisciplinar de Pós-Graduação em Estudos Étnicos e Africanos, da Universidade Federal da Bahia. 2011. Disponível em: < https://goo.gl/3V61Tb>. Acesso em: 25 de maio de 2015.

\section{Fontes e sites}

CARDOSO, Fernando Henrique. Discurso na cerimónia de entrega do Prémio Nacional dos Direitos Humanos. Palácio do Planalto, Brasília. 2001.

DIPLOMATIZZANDO. Ingresso no Itamaraty: pequena polemica em copo d'agua. Disponível em: <https://goo.gl/fnuf4j>. Acesso em 02 de novembro de 2014.

EXTRA GLOBO. A nova cara do Itamaraty. Disponível em: https://goo.gl/HZNfuW. Acesso em 12 junho de 2015 .

FOLHA ONLINE. Negros contam com o apoio de intelectuais para ingressar no Itamaraty. Disponível em: <https://goo.gl/Kpxolf>. Acesso em 20 de agosto de 2015.

INSTITUTO RIO BRANCO. Programa de açáo afirmativa. Disponível em: <https://goo.gl/ $11 w v N k>$. Acesso em 15 de junho de 2015.

ITAMARATY. Discurso do secretário José Ijino Santana. Disponível em: <https://goo. gl/7BYvbw>. Acesso em: 18 de novembro de 2015.

JUSBRASIL. Como e quando o Itamaraty discriminou Joaquim Barbosa. Disponível em: $<$ https://goo.gl/fPrJUu>. Acesso em 10 de outubro de 2015.

MACEDO, Ana Paula; JUNGBLUT, Cristiane. FH abre vagas para negros no curso preparatório para a prova do Itamaraty. O Globo, Rio de Janeiro-RJ, 20 de Dez. 2001. 
TARRAFEL, Andressa. Manoel Pio Corrêa Jr. (1918-2013) - O diplomata, as viagens e os livros. Folha de São Paulo. São Paulo. 2012. Disponível em: <https://goo.gl/5a2XPq>. Acesso em: 14 de novembro de 2015.

UOL. Minha História Benedicto Fonseca Filho, 47 . 2011. Disponível em: Http://Www1.Folha. Uol.Com.Br/Fsp/Mundo/Ft0601201107.Htm.

VEJA. O dia em que Joaquim Barbosa foi reprovado no Itamaraty. Disponível em: <https://goo. gl/cAl6sa>. Acesso em: 10 de abril de 2015.

\section{From Exclusion to Controlled Inclusion: blacks and women in Brazilian diplomacy}

\section{Abstract}

Intelligence, sophistication, keen taste (refined taste), mastery of several languages, established knowledge of art, culture and the use of label rules of etiquette. These aspects, in a naturalized way, compose the diplomatic habitus. The Brazilian diplomacy remained for a long time faithful to the norms and spaces that consecrated and distinguished it from the rest of Brazilian society, so that until the redemocratization Itamaraty was the reflection of its elite, this includes the expressive majority of white men. It was only in the second half of the 1990s that more effective measures were taken to diversify career staff. Considering the historical construction of the field, the diplomatic habitus and the measures adopted in the last decades, it's intended to investigate the forms of exclusion and inclusion of minorities, especially women and black people. The research on this social space is fundamental to the extent that the production about this field and its agents is very scarce. For the analysis were used quantitative and qualitative methods: survey, interviews, memoirs, biographies, database with geographic origin and school education, annuals and notices of concourse. .

Keywords: Itamaraty. Diplomats. Bureaucracy.

Recebido em 22/08/2017

Aprovado em: 23/11/2017 